\title{
Terapia cu oxid nitric la prematurii cu detresă respiratorie formă severă - prezentare de cazuri
}

\author{
Mihaela Demetrian', Georgeta Grecu' ${ }^{1}$, Andreea Vidru', \\ Andreea Calomfirescu-Avramescu', Alina Ciucă ${ }^{2}$, Anca Panaitescu ${ }^{3}$ \\ ${ }^{1}$ Spitalul Clinic „Filantropia“, Bucureşti, România \\ ${ }^{2}$ Spitalul Clinic de Urgență de Pediatrie „Grigore Alexandrescu“, Bucureşti, România \\ ¿Universitatea de Medicină și Farmacie „Carol Davila“, Bucureşti, România
}

\begin{abstract}
REZUMAT
Insuficiența respiratorie la prematuri poate fi complicată de hipertensiunea pulmonară care uneori nu răspunde la terapiile convenționale. Terapia convențională pentru hipertensiunea pulmonară implică suport respirator, ce include ventilația și presiunea continuă de distensie, administrarea de surfactant, sedarea și/sau relaxarea musculară, dacă este necesar. Circulația sistemică este adesea menținută cu agenți inotropi la prematurii cei mai bolnavi. Experiența noastră în terapia cu oxid nitric la prematurii sub 32 de săptămâni a început în urmă cu 5 ani. Există până în prezent 7 cazuri de prematuri cu insuficiență respiratorie care nu au răspuns la terapiile convenționale. În acest articol, vom prezenta cele mai sugestive cazuri de insuficiență respiratorie cu hipertensiune pulmonară severă ce au răspuns favorabil la administrarea de oxid nitric.
\end{abstract}

Cuvinte cheie: prematur, hipertensiune pulmonară, oxid nitric

\section{INTRODUCERE}

De la introducerea surfactantului, mortalitatea cauzată de insuficiența respiratorie la prematuri a scăzut semnificativ [1,2]. Cu toate acestea, unii prematuri nu prezintă o îmbunătățire adecvată a oxigenării după ce au primit tratament cu surfactant. Prematurii care beneficiază de suport respirator prezintă un risc crescut de displazie bronhopulmonară (BPD) ca urmare a injuriei pulmonare, care poate avea un impact semnificativ pe termen lung.

Reglarea tonusului muscular vascular la nivel celular are loc prin oxidul nitric (NO) [3]. Oxidul nitric este generat enzimatic din L-arginină de una dintre cele trei sintaze NO. NO activează guanililciclaza prin legarea la componenta sa heme, ceea ce duce la producerea monofosfatului de guanozină ciclică (cGMP), care provoacă vasodilatație [4]. NO poate fi amestecat cu gazele inspirate și livrat direct în căile respiratorii periferice, unde poate provoca vasodilatație locală.
Rezistența vasculară pulmonară este reglată de NO endogen [5] sau NO exogen [6]. În mai multe experimente pe modele de animale, hipertensiunea pulmonară a fost scăzută de inhalarea de oxid nitric exogen. În general, cercetătorii au observat un efect minor sau absent asupra circulației sistemice în cazul inhalării de oxid de azot (iNO). Studiile efectuate la adulţi şi la nou-născuți la termen au confirmat că iNO provoacă vasodilatație pulmonară selectivă, reducerea presiunii arteriale pulmonare și îmbunătăţirea raportului ventilație/perfuzie [7]. La nou-născuții la termen cu insuficiență respiratorie hipoxică, iNO scade necesarul de ECMO, dar nu scade mortalitatea totală [8] .

\section{PREZENTAREA DE CAZURI}

\section{Cazul 1}

Descriem cazul unui prematur, născut la $31+3$ săptămâni de gestaţie, cu insuficiență respiratorie hipoxică care nu a răspuns la terapia convențională ma- 
ximă. Sarcină urmărită: PPROM la 25 de săptămâni (total perioadă cu MR 42 zile). Profilaxie cu corticosteroizi, cură de antibiotice și tocolitice. Cezariană de urgență pentru suspiciune de corioamniotită și status fetal incert la 31 spt. +3 zile. La naștere: iniţial CPAP (Neopuf), apoi intubat din sala de nașteri, surfactant administrat în primele 30 de minute, ventilat iniţial convențional: SIMV+PSV FiO2 40-50\%, dar cu deteriorare progresivă respiratorie, rgf. pulmonară: pneumotorax drept (primele 60 minute), drenaj aspirativ pleural drept. La 6 ore de la naștere: $\mathrm{SpO} 2-80 \%$ SIMV + PSV (FiO2 80-90\%), acidoză mixtă: pH 7,01, pCO2 $78 \mathrm{mmHg}$, BB $11 \mathrm{mmol} / \mathrm{l}$, EB -13,4 mmol/l. Indexul de oxigenare (OI), calculat după formula: FiO

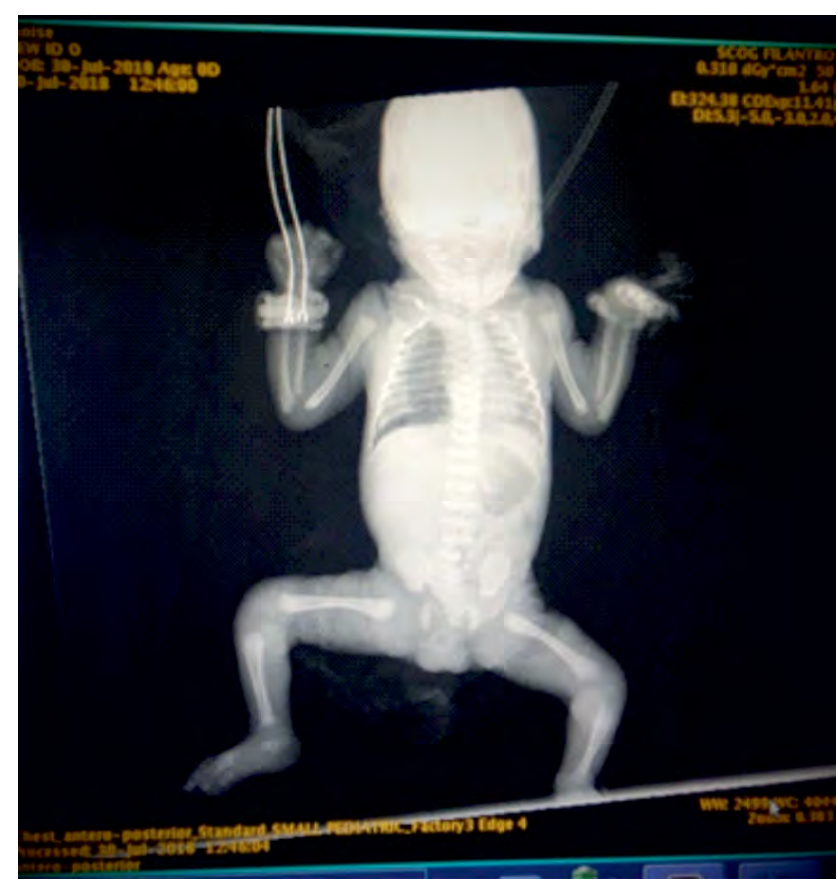

FIGURA 1. Cazul 1 - Radiografie cardiopulmonară - câteva ore după naștere

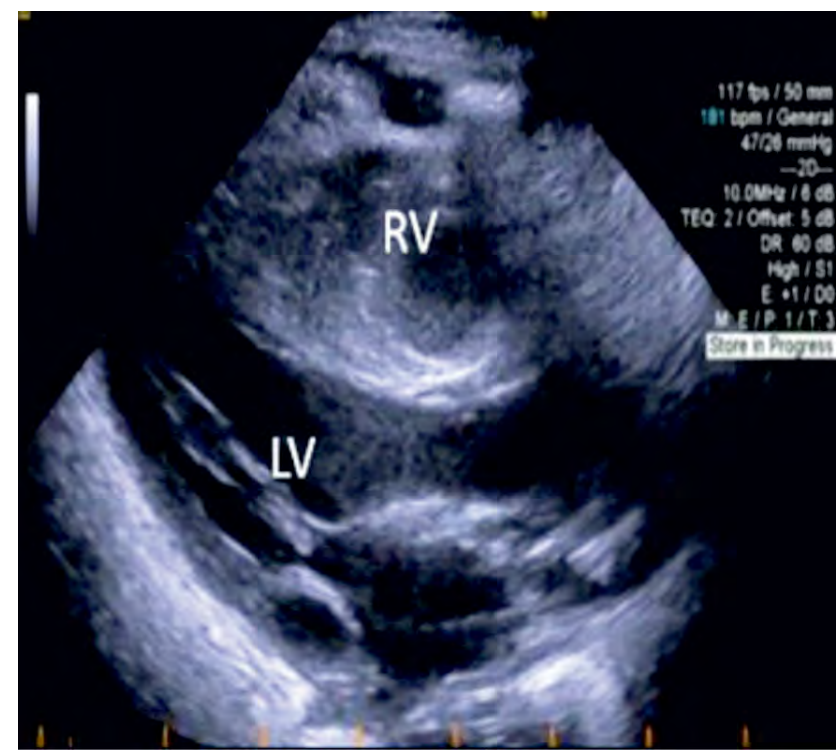

FIGURA 2. Cazul 1 - Ecografie cardiacă
2 x MAP x 100/PaO2 = 55. Se administrează a doua doză de surfactant; Dopamină + Dobutamină pentru susținere cardiocirculatorie. Eco cord: hipertensiune pulmonară (PAP 70-80 mmHg) cu şunt dreapta stânga. La 7 ore de viață, se iniţiază terapia cu iNO iniţial cu 15, apoi 20 ppm și se trece în HFOV; la 3-4 ore după inițierea tratamentului cu oxid nitric, saturație în oxigen mai stabilă $>90 \%$, se reduce treptat $\mathrm{FiO} 2$ (70-60-50\%), apoi iNO 18-15-14-10-5 ppm, cu renunțarea totală la administrare după 72 de ore. Rămâne ventilat convențional încă 4 zile, apoi HFNC încă 14 zile.

\section{Cazul 2}

Raportăm despre cazul unui nou-născut feminin născut la $30+1$ săptămâni de gestație prin cezariană de urgență pentru ruptura prematură a membranelor (PPROM). Este prima născută a unei sarcini gemelare bicorionice și biamniotice. La naștere: scor Apgar $1^{\prime}-5,5^{\prime}-8$, greutate la naștere 1380 g. Mai întâi, a avut nevoie de presiune nazală continuă pozitivă a căilor respiratorii (CPAP), urmată de intubația orotraheală. S-a administrat o doză de surfactant, apoi nounăscutul a fost transferat imediat la terapie intensivă neonatală. La internarea în unitatea noastră, stare generală gravă, hipotonă cu reactivitate redusă; saturația de oxigen a fost de 93-94\% (concentrație de oxigen inspirată (FiO2) 0,45). În primele ore după naștere, emisie de meconiu cu sânge; aspirat gastric sanguinolent. Analiza gazelor arteriale și investigațiile de rutină au fost normale. Coagularea a fost perturbată cu timp de protrombină și timp parțial de tromboplastină prelungite. Aceasta a fost corectată prin administrarea de PPC.

În orele următoare, starea respiratorie s-a deteriorat. Radiografia toracică a evidențiat prezența infiltratelor pulmonare, în principal la plămânul stâng, și a fost administrată o a doua doză de surfactant. Ecografia craniană a fost normală. Ecocardiografia a arătat patent ductus arteriosus (PDA) şi insuficiență tricuspidiană (PAP 40-45 mmHg), dar tratamentul cu ibuprofen nu a fost început din cauza tulburărilor de sângerare. În a doua zi de viaţă, s-a repetat ecocardiografia, prezentând PDA cu flux pulsatil. Coagularea a fost normalizată, astfel încât am putut începe tratamentul cu ibuprofen (prima doză $10 \mathrm{mg} / \mathrm{kg}$ ). A fost inițiat tratamentul cu antibiotice cu spectru larg.

În a treia zi de viață, condițiile generale ale pacientului s-au deteriorat în continuare. Saturaţia de oxigen a fost de $80 \%$ în timpul ventilaţiei sincrone intermitente (SIMV) cu FiO2 0,80-0,90. Am observat o acidoză respiratorie severă (pH 6,93, pCO2 75 mmHg, bicarbonat $11 \mathrm{mmol} / \mathrm{l}$, exces de bază $-15,9 \mathrm{mmol} / \mathrm{l})$. 
A fost administrată a treia doză curosurf și bicarbonat de sodiu; simultan s-a început perfuzia continuă de dopamină. Indicele de oxigenare $(\mathrm{OI})$, calculat ca FiO2 $x$ media airway pressure $\times 100 / \mathrm{PaO} 2(\mathrm{mmHg})$, a fost de 32. Ecocardiografia a prezentat hipertensiune pulmonară severă (PAPs $77-80 \mathrm{mmHg}$ ) cu șunt dreapta la stânga. Date fiind starea critică și constatarea hipertensiunii pulmonare severe, am decis să oprim ibuprofenul și să începem terapia cu iNO. iNO a fost început la doza de 10 p.p.m. iar nou-născutul a fost ventilat în SIPPV (FiO2 0,95). După 1 h, iNO a fost crescut la 15 p.p.m. iar ventilația mecanică convențională a fost schimbată la oscilație de înaltă frecvență (HFOV). Opt ore după începerea tratamentului, saturaţia oxigenului și parametrii gazelor din sânge s-au îmbunătățit și am redus iNO la 13, 10 și 7,5 p.p.m. treptat. În același timp, ventilația mecanică convențională a fost repornită și $\mathrm{FiO} 2$ a fost redus progresiv la 0,50 .

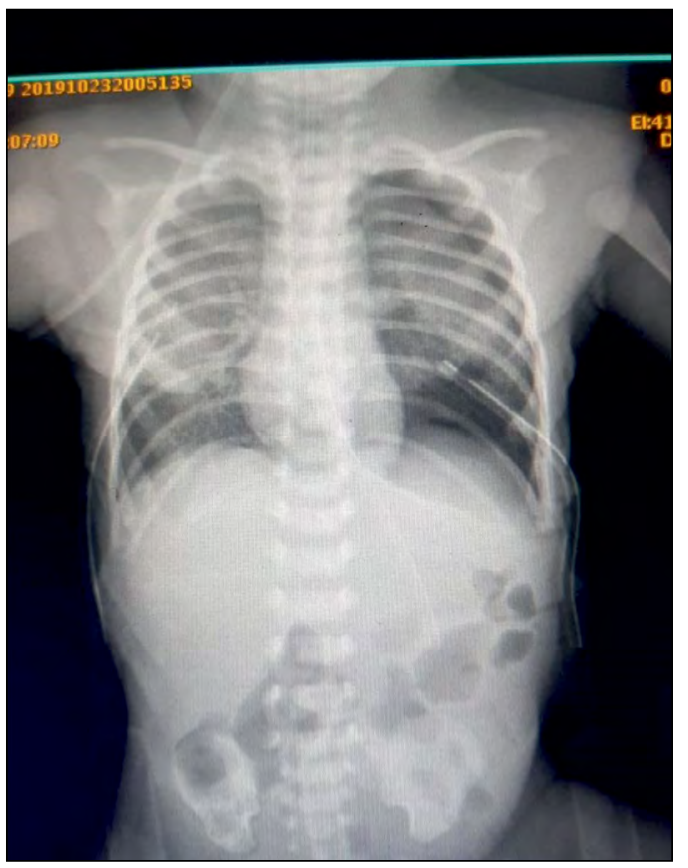

FIGURA 3. Cazul 2 - Radiografie cardiopulmonară

După 42 de ore de tratament, ecocardiografia a arătat o presiune pulmonară normală și PDA cu șunt aproape total de la stânga spre dreapta. Indicele de oxigenare a fost de 16. iNO a fost oprit progresiv, ajungând la suspendarea completă după 50 de ore de la începutul tratamentului. Am continuat ventilația mecanică convențională (SIMV), coborând treptat $\mathrm{FiO} 2$, iar la 60 de ore de la suspendarea iNO a fost extubată.

Ecografia craniană efectuată la $32+5 \mathrm{VG}$ a fost normală. A fost efectuată o ecocardiografie de urmărire, ultima (la $34 \mathrm{VG}$ ) care prezintă presiune pulmonară normală, fără șunturi și ductus arteriosus închis.

\section{Cazul 3}

Descriem cazul unui prematur de sex masculin născut la 29 2/7 săptămâni prin operație cezariană din prezentație craniană după ruperea prematură a membranelor la 26 săptămâni. La naștere scor Apgar 5/6/6, greutate $1.400 \mathrm{~g}$. Resuscitare respiratorie cu CPAP pe mască eșuată din cauza respirațiilor ineficiente. Se intubează din sala de nașteri și se administrează surfactant $200 \mathrm{mg} / \mathrm{kg}$, apoi ventilat mod HFOV cu volum garantat. În următoarele ore, saturația în oxigen menținută la $89-92 \%$ cu concentrație a oxigenului inspirat peste $60 \%$, instabil hemodinamic cu suport inotrop cu Noradrenalină și Dobutamină. Din cauza desaturărilor frecvente și a creșterii parametrilor de ventilație, la 12 ore de viață se administrează a doua doză de surfactant. Nu se obține o ameliorare evidentă, saturația de 70-80\% la concentrație de oxigen de 80\%. Radiografie pulmonară evidențiază expansionare normală a plămânilor la coasta a 9-a. Ecocardiografia a demonstrat hipertensiune pulmonară severă (PAPs $80 \mathrm{mmHg}$ ) cu șunt dreapta la stânga. Se decide administrarea de oxid nitric $20 \mathrm{ppm}$ concomitent $\mathrm{cu}$ HFOV cu VG. La scurt timp după instalarea sistemului de administrare de oxid nitric, saturația crește ajungând peste $90 \%$ în aproximativ două ore. Se scade treptat concentrația oxigenului inspirat până la $40 \%$ și se menține administrarea de oxid nitric timp de 72 de ore, se detubează după 5 zile. Rămâne oxigenodependent până la 35 de săptămâni. Ecografia cardiacă efectuată la 32 de săptămâni cu aspect normal, fără semne de hipertensiune pulmonară.

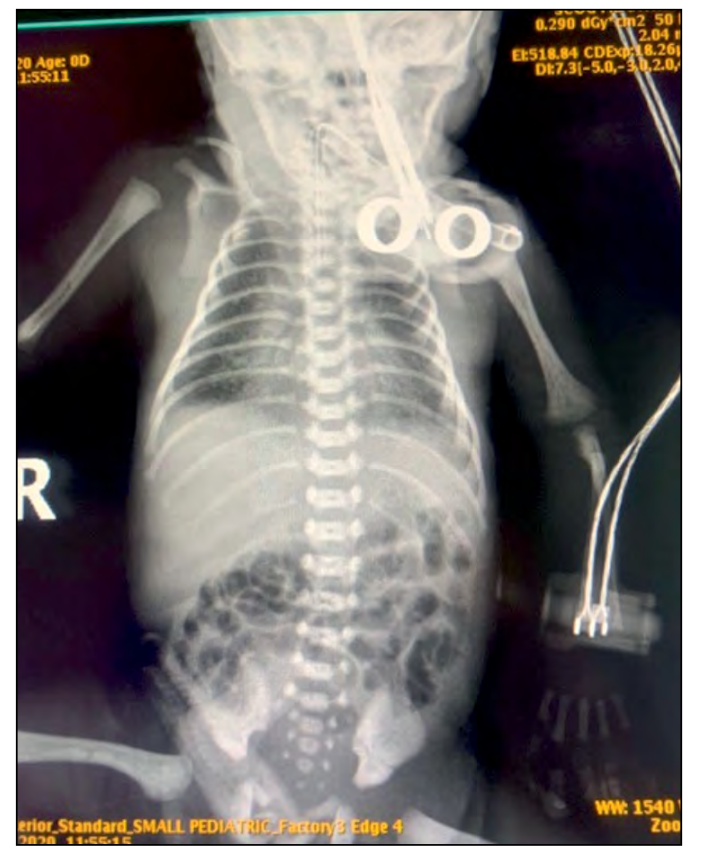

FIGURA 4. Cazul 3 - Radiografie cardiopulmonară 


\section{DISCUȚII}

Deși iNO a fost aprobat pentru tratamentul PPHN la nou-născuții la termen și în apropierea termenului, eficacitatea acestei terapii pentru insuficiența respiratorie hipoxică acută la prematuri nu este clară. Ca urmare a diferențelor de fiziopatologie, a criteriilor de selectare și a rezultatelor diferite, rezultatele tratamentului la nou-născuții la termen nu pot fi extrapolate la prematuri. Criteriile de intrare utilizate pentru studiile iNO la nou-născuții la termen au implicații diferite pentru nou-născutul prematur, deoarece, la aceleași niveluri ale indicelui de oxigenare (OI), mortalitatea este mult mai mare. Deși presiunea arterei pulmonare este crescută la prematurii cu insuficiență respiratorie, ea produce rar inversarea șuntului prin ductul arterial. Prin urmare, profilul hemodinamic diferă oarecum de cel al nou-născutului la termen. ECMO nu este utilizat pentru prematuri din cauza îngrijorărilor cu privire la complicațiile hemoragice; prin urmare, cerința pentru ECMO nu poate fi utilizată ca un criteriu. Experimentele făcute pe modele animale cu BPD sugerează că un tratament prelungit cu iNO poate modifica leziunile pulmonare [9]. Oxidul nitric inhalat are efecte care pot reduce inflamația pulmonară și pot îmbunătăți remodelarea vasculară în plămânul prematur cu leziuni acute.

Dacă terapia cu iNO duce la o scădere a necesităţii de susținere ventilatorie, reducerea leziunilor pulmonare poate duce la prevenirea sau ameliorarea BPD. Oxidul nitric participă atât la producerea, cât și la protecția împotriva leziunilor oxidative [10]. Prin urmare, efectele terapiei cu iNO asupra plămânilor în curs de dezvoltare merită o evaluare atentă înainte de introducerea iNO în practica clinică.

Preocuparea deosebită la prematuri este efectul iNO asupra coagulării. S-a dovedit că oxidul nitric inhalat crește timpul de sângerare la voluntarii adulți, precum și la adulții cu ARDS [11]. Acest lucru pare să apară prin mecanisme dependente de cGMP; se presupune că cGMP plachetar este crescut în timpul trecerii trombocitelor prin plămân. Prematurii prezintă un risc ridicat de a dezvolta hemoragie intraventriculară (IVH), ceea ce are efecte substanțiale asupra rezultatelor dezvoltării pe termen lung. Prin urmare, este important ca studiile să evalueze iNO în ceea ce privește efectul său asupra incidenței HIV la prematuri. Puținele raportări de caz și serii de cazuri publicate înainte de studiile randomizate controlate (RCT) au demonstrat că prematurii cu insuficiență respiratorie severă, care nu au răspuns la tratamentul convențional, inclusiv surfactant și ventilație cu frecvență înaltă, pot avea o oxigenare îmbunătătită cu
iNO [12]. Aceste studii s-au concentrat în special pe mortalitatea și incidența HIV.

Studii mai recente pe animale, care arată efectele directe ale iNO în protejarea plămânului prematur împotriva efectelor adverse ale hiperoxiei [13] și susținerea dezvoltării microvasculare, sugerează posibile beneficii directe pentru reducerea DBP. Alte recenzii sistematice publicate despre iNO la prematur sunt neconcludente.

Oxidul nitric inhalat (iNO) a fost aprobat pentru tratamentul PPHN la nou-născuții la termen sau în apropierea termenului. S-a demonstrat că acțiunea sa vasodilatatoare selectivă asupra circulației pulmonare îmbunătățește oxigenarea și reduce nevoia de (ECMO) oxigenare prin membrană extracorporeală [14-20].

$\mathrm{Cu}$ toate acestea, rolul său în gestionarea insuficienței respiratorii hipoxice datorate hipertensiunii pulmonare la prematuri nu este clar. Linii directoare sau protocoale standardizate nu există, dar unele studii au arătat că iNO ar putea fi utilizat ca terapie de salvare la nou-născuți prematuri cu hipertensiune pulmonară severă care nu răspund la terapia convențională maximă [21-25].

Diferite studii au arătat că iNO ar putea fi utilizat ca terapie de salvare la prematurii cu hipertensiune pulmonară severă $[8,9]$. În special, se pare că răspunsul la iNO se îmbunătățește semnificativ odată cu creșterea vârstei gestaționale: nou-născuții născuți $\geq 29 \mathrm{VG}$ au un răspuns semnificativ mai mare în comparație cu nou-născuții < 29 VG [10]. Cele mai recente studii concluzionează că terapia cu iNO poate îmbunătăți oxigenarea la sugarii foarte prematuri cu PPHN, dar nu este recomandată pentru tratamentul de rutină și trebuie luată în considerare cu atenție. Mai mult, ei sugerează că FiO2 $>0,65$, diagnosticul ecocardiografic al PPHN și greutatea la naștere $>750 \mathrm{~g}$ prezic în mod independent un efect benefic al iNO la prematuri cu RDS. Este dificil să se stabilească cauza hipertensiunii pulmonare la pacienții noștri, dar, probabil, rezultă din modificarea semnificativă a fluxurilor pulmonare (cu o componentă vasoconstrictivă crescută) secundară unui factor matern precum PPROM [10]. Cu toate acestea, nu putem exclude că administrarea de ibuprofen pentru închiderea PDA a fost declanșatorul care a dus la apariția hipertensiunii pulmonare. De fapt, hipertensiunea pulmonară este un efect secundar rar, dar potențial letal, la prematurii care primesc ibuprofen pentru închiderea PDA [26,27].

\section{CONCLUZII}

La prematurii foarte bolnavi care îndeplinesc criteriile pentru o oxigenare slabă, terapia de salvare cu 
iNO trebuie aplicată atunci când terapiile convenționale au eșuat. În unitatea noastră, terapia iNO este utilizată la nou-născuții prematuri cu hipertensiune pulmonară persistentă (PPHN) atunci când terapia convențională maximă (FiO2 0,80-0,90) nu funcționează.

De asemenea, este important de menționat modul în care condițiile pacientului s-au îmbunătăţit atunci când iNO a fost asociat cu HFOV mai degrabă decât cu ventilația mecanică convențională, confirmând eficacitatea asocierii dintre iNO şi HFOV pentru tratamentul PPHN.

\section{BIBLIOGRAFIE}

1. Walther FJ, Benders MJ, Leighton JO. Persistent pulmonary hypertension in premature neonates with severe respiratory distress syndrome. Pediatrics. 1992;90(6):899-904.

2. Soll RF. Prophylactic natural surfactant extract for preventing morbidity and mortality in preterm infants. Cochrane Database Syst Rev. 2000;1997(2):CD000511.

3. Abman SH, Chatfield BA, Hall SL, McMurtry IF. Role of endotheliumderived relaxing factor during transition of pulmonary circulation at birth. American Journal of Physiology 1990;259:H1921-7.

4. Finer NN, Barrington KJ. Nitric oxide therapy for the newborn infant. Seminars in Neonatology 1998;3:127-36.

5. Cornfield DN, Chatfield BA, McQueston JA, McMurtry IF, Abman SH. Effects of birth-related stimuli on L-arginine-dependent pulmonary vasodilation in ovine fetus. American Journal of Physiology 1992; 262:H1474-81.

6. Kinsella JP, McQueston JA, Rosenberg AA, Abman SH. Hemodynamic effects of exogenous nitric oxide in ovine transitional pulmonary circulation. American Journal of Physiology 1992; 263:H875-80.

7. Rossaint R, Falke KJ, Lopez F, Slama K, Pison U, Zapol WM. Inhaled nitric oxide for the adult respiratory distress syndrome. New England Journal of Medicine 1993;328:399-405.

8. Finer NN, Barrington KJ. Nitric oxide for respiratory failure in infants born at or near term. Cochrane Database Syst Rev. 2006; (4):CD000399.

9. Bland RD, Albertine KH, Carlton DP, MacRitchie AJ. Inhaled nitric oxide effects on lung structure and function in chronically ventilated preterm lambs. American Journal of Respiratory and Critical Care Medicine 2005;172:899-906.

10. McAndrew J, Patel RP, Jo H, Cornwell T, Lincoln T, Moellering D, et al. The interplay of nitric oxide and peroxynitrite with signal transduction pathways: implications for disease. Seminars in Perinatology 1997; 21:351-66

11. Samama CM, Diaby M, Fellahi JL Mdhafar A, Eyraud D, Arock M. Inhibition of platelet aggregation by inhaled nitric oxide in patients with acute respiratory distress syndrome. Anesthesiology 1995;83:56-65.

12. Meurs KP, Rhine WD, Asselin JM, Durand DJ, Premie INO Collaborative Group. Response of premature infants with severe respiratory failure to inhaled nitric oxide. Pediatric Research 1997; 41:271A (Abstract).

13. Bland RD, Albertine $\mathrm{KH}$, Carlton DP, MacRitchie AJ. Inhaled nitric oxide effects on lung structure and function in chronically ventilated preterm lambs. American Journal of Respiratory and Critical Care Medicine 2005;172:899-906.

14. Roberts JD, Polaner DM, Zapol WM, Lang P. Inhaled nitric oxide in persistent pulmonary hypertension of the newborn. Lancet. 1992; 340(8823):818-819.
În concluzie, experiența noastră confirmă faptul că tratamentul cu INO trebuie considerat ca o terapie de salvare la nou-născuții prematuri cu insuficiență respiratorie hipoxică acută cauzată de hipertensiune pulmonară severă. Sunt necesare studii suplimentare și studii clinice pentru a determina mai bine eficacitatea reală a acestei terapii la prematuri și mai ales la cei cu prematuritate extremă pentru a defini ghiduri şi protocoale standard.

Conflict of interest: none declared Financial support: none declared

15. Neonatal Inhaled Nitric Oxide Study Group Inhaled nitric oxide in full-term and nearly full-term infants with hypoxic respiratory failure. N Engl J Med. 1997;336(9):597-604.

16. Roberts JD, Jr, Fineman JR, Morin FC, Shaul PW, Rimar S, Schreiber $M D$, The Inhaled Nitric Oxide Study group et al. Inhaled nitric oxide and persistent pulmonary hypertension of the newborn. N Engl J Med. 1997;336(9):605-610.

17. Al-Alaiyan S, Neiley E. Inhaled nitric oxide in persistent pulmonary hypertension of the newborn refractory to high-frequency ventilation. Crit Care. 1999;3(1):7.

18. Clark RH, Kueser TJ, Walker MW, Southgate WM, Huckaby JL, Perez JA, Roy BJ, Keszler M, Kinsella JP. Low-dose nitric oxide therapy for persistent pulmonary hypertension of the newborn. N Engl J Med. 2000; 342(7):469-474.

19. Barrington KJ, Finer N, Pennaforte T, Altit G. Nitric oxide for respiratory failure in infants born at or near term. Cochrane Database Syst Rev. 2017;1(1):CD000399.

20. Kinsella JP, Cutter GR, Walsh WF, Gerstmann DR, Bose CL, Hart C, Sekar KC, Auten RL, Bhutani VK, Gerdes JS, George TN et al. Early inhaled nitric oxide therapy in premature newborns with respiratory failure. N Engl J Med. 2006;355(4):354-364.

21. Donohue PK, Gilmore MM, Cristofalo E, Wilson RF, Weiner JZ, Lau $\mathrm{BD}$, Robinson KA, Allen MC. Inhaled nitric oxide in preterm infants: a systematic review. Pediatrics. 2011;127(2):e414-e422.

22. Kumar VH, Hutchison AA, Lakshminrusimha S, Morin FC, Wynn RJ, Ryan RM. Characteristics of pulmonary hypertension in preterm neonates. J Perinatol. 2007;27(4):214-219.

23. Barrington KJ, Finer N, Pennaforte T. Inhaled nitric oxide for respiratory failure in preterm infants. Cochrane Database Syst Rev. 2017;1(1):CD000509.

24. Dani C, Corsini I, Cangemi J, Vangi V, Pratesi S. Nitric oxide for the treatment of preterm infants with severe RDS and pulmonary hypertension. Pediatr Pulmonol. 2017;52(11):1461-1468.

25. Baczynski M, Ginty S, Weisz DE, McNamara PJ, Kelly E, Shah P, Jain A. Short-term and long-term outcomes of preterm neonates with acute severe pulmonary hypertension following rescue treatment with inhaled nitric oxide. Arch Dis Child Fetal Neonatal Ed. 2017; 102(6):F508-F514.

26. Gournay V, Savagner C, Thiriez G, Kuster A, Roze JC. Pulmonary hypertension after ibuprofen prophylaxis in very preterm infants. Lancet. 2002;359(9316):1486-1488.

27. Bellini C, Campone F, Serra G. Pulmonary hypertension following L-lysine ibuprofen therapy in a preterm infant with patent ductus arteriosus. Can Med Assoc J. 2006;174(13):1843-1844. 